\title{
ATIVIDADE ANTIMICROBIANA DE EXTRATOS VEGETAIS FRENTE À BACTÉRIAS DE IMPORTÂNCIA MÉDICA
}

\section{Flávia Sarlo Gomes Dutra}

Farmacêutica/Faculdade de Medicina de Campos

flaviasgdutra@hotmail.com

\author{
Lanamar de Almeida Carlos \\ Doutora em Produção Vegetal \\ Universidade Federal de São João del-Rei-CSL \\ lanamar@ufsj.edu.br
}

\section{Olney Vieira da Motta}

Doutor em Produção Animal

Universidade Estadual do Norte Fluminense Darcy Ribeiro-LSA

olney@uenf.br

\author{
Alexandre Pio Vianna \\ Doutor em Produção Vegetal \\ Universidade Estadual do Norte Fluminense Darcy Ribeiro-LMGV \\ Pirapora@uenf.br
}

\section{Silvia Menezes Faria Pereira}

Doutora em Engenharia e Ciência dos Materiais

Universidade Estadual do Norte Fluminense Darcy Ribeiro-LTA

silvia@uenf.br

\section{RESUMO}

O uso indiscriminado de antimicrobianos determina um processo de seleção de micro-organismos patogênicos que apresentam resistência à maioria dos compostos químicos utilizados na agropecuária e na medicina. Uma alternativa eficaz e econômica tem sido o desenvolvimento e o uso de produtos naturais com propriedades antimicrobianas. Este trabalho teve como objetivo avaliar a atividade antimicrobiana de extratos de Punica granatum, Anacardium occidentale e Psidium guajava frente a cepas de Stafhylococcus aureus, Stafhylococcus epidermidis, Escherichia coli e Pseudomonas aeruginosa. A investigação foi conduzida utilizando o método de difusão em ágar e inóculo bacteriano padronizado, com poços perfurados no ágar, nos quais foram adicionados volumes conhecidos das substâncias testadas: gentamicina (controle positivo), DMSO (controle negativo) e extratos vegetais. As placas foram incubadas a $37^{\circ} \mathrm{C}$ por 24 horas e mensurado o diâmetro dos halos de inibição. Os extratos diclorometânico e metanólico das cascas de Punica granatum e metanólicos das folhas de Anacardium occidentale e Psidium guajava, na concentração de 1 $\mathrm{g} / \mathrm{ml}$, foram mais efetivos contra as cepas de S. aureus, S. epidermidis, E.coli. Posteriormente, esses extratos foram utilizados para o teste de sinergismo em associação a antibióticos padronizados, no qual foi observado efeito sinérgico frente às bactérias testadas, com exceção da $P$. aeruginosa.

Palavras-Chave: Extratos fitoquímicos. Agentes antibacterianos. Sinergismo farmacológico.

Persp. online: biol. \& saúde, Campos dos Goytacazes, 20 (6), 1- 13, 2016

seer.perspectivasonline.com.br 


\section{ABSTRACT}

The indiscriminate use of antibiotics for agriculture and medical purposes determinates a selection process of pathogenic microorganisms that are resistant to the most used chemical components. An inexpensive and effective alternative is the development and use of natural products with antimicrobial activity. This study has the objective of evaluate the antimicrobial activity of Punica granatum, Anacardium occidentale and Psidium guajava extracts towards Stafhylococcus aureus, Stafhylococcus epidermidis, Escherichia coli and Pseudomonas aeruginosa strains. The investigation was conducted by the Ágar Diffusion assay, using a standardized bacterial inoculation, by adding known volumes of the tested substances in ágar drilled wells: gentamicin (positive control), DMSO (negative control) and plant extracts. Further the Petri dishes were incubated at $37^{\circ} \mathrm{C}$ for 24 hours, and the inhibition zones diameters were measured. The dichloromethanic and methanolic extracts of Punica granatum's shell and methanolic extracts of Anarcadium occidentale and Psidium guajava's leaves, in the concentration of $1 \mathrm{~g} / \mathrm{ml}$, were the most effective against $S$. aureus, $S$. epidermidis, and E. coli's strains. Later, these extracts were tested for sinergism, in association to standard antibiotics. The sinergic effect was observed except with $P$. aeruginosa.

Keyword: Phytochemistry extracts. Antibacterial agents. Pharmacological sinergism.

\section{INTRODUÇÃO}

De acordo com a Organização Mundial de Saúde (OMS), $80 \%$ da população dos países em desenvolvimento dependem da medicina tradicional para as suas necessidades básicas de saúde e cerca de 85\% da medicina tradicional envolve o uso de extratos de plantas (AZEVEDO; SILVA, 2006). Desde 1977, a OMS incentiva o estudo de plantas medicinais, a fim de avaliar os benefícios da utilização de medicamentos fitoterápicos e de conhecer os riscos de seu uso indevido (YUNES; CALIXTO, 2001).

Muitos trabalhos científicos são feitos estudando as propriedades medicinais da romãzeira (Punica granatum L.), família Punicacea (WERKMAN et al., 2008; BHOWMIK, et al., 2013; MIGUEL, et al., 2010). A punicalagina, um tanino elágico derivado do fruto da $P$. granatum, é provavelmente um dos principais constituintes antimicrobianos desta fruta (MACHADO et al., 2002). Toda a planta contém, entre os seus princípios ativos, tanino em grande quantidade (em torno de $22 \%$ a $25 \%$ de ácido punicotânico). Os alcalóides pelieterina e isopelieterina estão presentes de $0,3 \%$ a $0,9 \%$ nas cascas da raiz e do fruto. A casca do fruto também contém taninos e alcalóides, além de substâncias com ação antibiótica, antisséptica, antiviral e adstringente (CARVALHO et al., 2002).

Segundo Carvalho et al., (2002), as folhas de goiabeira (Psidium guajava L.) família Myrtaceae, apresentam taninos, óleos essenciais, triterpenóides e $\beta$-sitosterol em sua constituição. Possui atividade antimicrobiana, antimutagênica e atividade hipoglicêmica, dentre outras. Na medicina popular é utilizada para cólicas, colite, diarréia, disenteria e dor de barriga (IHA et al., 2008).

O cajueiro (Anacardium occidentale L.), é utilizado na medicina tradicional, principalmente no nordeste brasileiro com efeitos terapêuticos como no tratamento de dores de dente, bronquites, artrites, cólicas intestinais, icterícia, diabetes, asma, anti-inflamatório para gengiva e garganta e até mesmo utilizado como afrodisíaco. Na literatura encontram-se atividades farmacológicas comprovadas, como sendo o cajueiro uma planta anti-iflamatória, antidiabética, inibidor da enzima acetilcolinesterase e substâncias isoladas do fruto demonstraram ser inibidora de tirosinase (SILVA et al., 2007).

Um dos grandes desafios da medicina humana e veterinária tem sido o manejo adequado das intercorrências infecciosas bacterianas e fúngicas que acometem os indivíduos nas respectivas áreas. Apesar da disponibilização de novos antibióticos, o ritmo do desenvolvimento de resistência bacteriana nos diferentes patógenos tem aumentado e representa um constante desafio terapêutico, fenômeno observado em todo mundo (ROSSI; ANDREAZZI, 2005). O uso indiscriminado e prolongado de antimicrobianos

Persp. online: biol. \& saúde, Campos dos Goytacazes, 20 (6), 1- 13, 2016

seer.perspectivasonline.com.br 
determina um processo de seleção de micro-organismos patogênicos mutantes que apresentem resistência a compostos químicos utilizados comumente, o que torna o uso de antimicrobianos de origem natural uma alternativa eficaz e econômica (VARGAS, et al., 2004). Assim, a busca de propriedades antibacterianas de extratos de plantas e de substâncias isoladas de plantas torna este trabalho relevante, no que diz respeito ao uso de antimicrobianos em medicina humana e veterinária.

O objetivo deste estudo foi avaliar a atividade de extratos de Punica granatum, Anacardium occidentale e Psidium guajava frente a cinco cepas de Stafhylococcus aureus, uma cepa de Stafhylococcus epidermidis, uma cepa de Escherichia coli e uma cepa Pseudomonas aeruginosa.

\section{MATERIAL E MÉTODOS}

\subsection{Material vegetal}

Os frutos de Punica granatum L. (romã) foram coletados em quintais de duas casas do centro de Campos dos Goytacazes - RJ. As folhas de Anacardium occidentale L. (cajueiro) e Psidium guajava L. (goiabeira) foram coletadas na Unidade de Apoio à Pesquisa em Zootecnia (Escola Estadual Antônio Sarlo), em Campos dos Goytacazes - RJ.

\subsection{Obtenção dos extratos vegetais}

Os extratos foram obtidos a partir das cascas e das sementes dos frutos de $P$. granatum, e das folhas de A. occidentale e P. guajava. O material vegetal foi seco em estufa de ventilação forçada de ar (Marconi®, modelo MA035) a $55^{\circ} \mathrm{C}$ por 72 horas. Os materiais secos foram triturados com o auxílio de um moinho de facas (Marconi®, modelo MA840).

O processo de extração foi feito por percolação usando solventes orgânicos (diclorometano e metanol), conforme descrito por Carlos et al. 2010). As soluções obtidas a partir das espécies vegetais foram destiladas a pressão reduzida em evaporador rotativo (Fisatom ${ }^{\circledR}$, modelo 802 ), dando origem aos extratos descritos no Quadro 1. Após eliminação dos solventes, os extratos foram solubilizados em DMSO (dimetilssulfóxido), obtendo a concentração de $1 \mathrm{~g} / \mathrm{mL}$.

Quadro 1 Descrição dos extratos vegetais

\begin{tabular}{rlll}
\hline $\mathbf{N}^{\mathbf{r}}$ & \multicolumn{1}{c}{ Planta } & \multicolumn{1}{c}{ Amostra } & \multicolumn{1}{c}{ Solvente } \\
\hline $\mathbf{1}$ & P. granatum & Casca do fruto & Diclorometano \\
$\mathbf{2}$ & P. granatum & Casca do fruto & Metanol \\
$\mathbf{3}$ & P. granatum & Semente & Diclorometano \\
$\mathbf{4}$ & P. granatum & Semente & Metanol \\
$\mathbf{5}$ & P. guajava & Folha & Metanol \\
$\mathbf{6}$ & A. occidentale & Folha & Metanol \\
\hline
\end{tabular}

\section{Micro-organismos}

Foram utilizadas cinco cepas de Staphylococcus aureus, descritas no Quadro 2, uma cepa de Staphylococcus epidermidis (ATCC 12228), uma de Pseudomonas aeruginosa (ATCC 27853) e uma de Escherichia coli (ATCC 25922). Todos os micro-organismos foram fornecidos pelo Laboratório de Sanidade Animal da UENF.

Persp. online: biol. \& saúde, Campos dos Goytacazes, 20 (6), 1- 13, 2016

seer.perspectivasonline.com.br 
Quadro 2. Cepas de Staphylococcus aureus

\begin{tabular}{ll}
\hline \multicolumn{1}{c}{ Cepa } & \multicolumn{1}{c}{ Descrição } \\
\hline ATCC 25923 & Cepa padrão para testes de sensibilidade a drogas \\
COL & $\begin{array}{l}\text { Cepa correspondente ao perfil meticilina-resistente (MRSA) } \\
\text { Cepa clínica secretora de enterotoxinas, isolada de leite de vacas com } \\
\text { mastite subclínica em rebanho da região norte fluminense }\end{array}$ \\
ATCC 55620 & RN6390B cepa selvagem agr positivo \\
S. aureus clínica & $\begin{array}{l}\text { Cepa clínica isolada de úlcera humana de paciente portador de } \\
\text { Diabetes mellitus em Campos dos Goytacazes-RJ }\end{array}$ \\
\hline
\end{tabular}

\subsection{Preparo dos inóculos}

As bactérias foram reativadas em placas de Petri contendo ágar BHA (Brain Heart ágar, Himedia ${ }^{\circledR}$ ), levadas em estufa tipo B.O.D. (Cientec ${ }^{\circledR}$, modelo CT705) a $37^{\circ} \mathrm{C}$ por 24 horas. A concentração de cada inóculo foi obtida através da transferência de colônias ativadas para solução salina estéril até atingir uma turbidez equivalente a concentração de $0,5 \mathrm{McF}$ em fotômetro (Densimat ${ }^{\circledR}$, bioMérieux, França), equipado para comprimento de onda $550 \mathrm{~nm}$.

\subsection{Avaliação da Atividade Antimicrobiana}

\subsubsection{Método de difusão em ágar}

O ensaio foi realizado de acordo com o método de Kirby-Bauer modificado, descrito por Barbosa et al. (1988) e Rojas et al. (2006).

Após o preparo e solidificação do ágar BHA, o mesmo foi perfurado com o auxilio de um perfurador formando oito orifícios circulares com $5 \mathrm{~mm}$ de diâmetro. Suspensões dos micro-organismos foram semeadas na superfície do meio, com auxílio de um swab estéril. Nos orifícios circulares foram colocados individualmente $50 \mu \mathrm{L}$ de cada extrato fitoquímico $(1 \mathrm{~g} / \mathrm{mL}$ ), separadamente (orifícios 1 a 6 , conforme ilustrado na Figura 1), $50 \mu \mathrm{L}$ do antibiótico gentamicina (orifício $\mathrm{G}$ - Figura 1) $(10 \mathrm{mg} / \mathrm{mL}$ ) e $50 \mu \mathrm{L}$ do solvente DMSO (orifício D, ilustrado na Figura 1), que foi utilizado para solubilizar e/ou diluir os extratos para esta avaliação. As placas foram incubadas em estufa tipo B.O.D. a $37^{\circ} \mathrm{C}$, durante 24 horas. Os diâmetros dos halos de inibição foram medidos com o auxilio de um paquímetro digital ATAGO e os resultados foram expressos em milímetros.

\subsubsection{Teste de sinergismo com discos antimicrobianos}

Os extratos 2, 5 e 6, que apresentaram maior atividade inibitória sobre as cepas testadas pelo método de difusão em ágar, foram submetidos a uma diluição em ágar Mueller Hinton (Himedia®). Inicialmente os extratos foram solubilizados em 6,0 mL de DMSO e posteriormente foram adicionados ao ágar Mueller Hinton $(\mathrm{MH})$ de maneira a se obter a concentração final de $50 \mu \mathrm{g}$ do extrato/ $\mathrm{mL}$ de ágar. O inóculo microbiano foi semeado na superfície do ágar acrescido de extrato, contido nas placas de Petri com o auxilio de um swab estéril. Após a inoculação, os discos antimicrobianos foram colocados na superfície das placas semeadas com auxílio de uma pinça estéril. Em seguida, as placas foram levadas a estufa tipo B.O.D. a $37^{\circ} \mathrm{C}$ por 24 horas.

As drogas testadas frente às bactérias citadas no Quadro 2 foram: tetraciclina (TET, $30 \mu \mathrm{g}$, Laboclin ${ }^{\circledR}$ ), cotrimoxazol (SUT, $25 \mu \mathrm{g}$, Laboclin ${ }^{\circledR}$ ), clindamicina (CLI, $2 \mu \mathrm{g}$, Laboclin $®$ ), amoxicilina + ácido clavulânico (AMC, 20/10 $\mu \mathrm{g}$, Sensifar ${ }^{\circledR}$ ), penicilina (PEN, 10 UI, Sensifar ${ }^{\circledR}$ ), eritromicina (ERI, 15

Persp. online: biol. \& saúde, Campos dos Goytacazes, 20 (6), 1- 13, 2016

seer.perspectivasonline.com.br 
$\mu \mathrm{g}$, Laboclin ${ }^{\circledR}$ ), vancomicina (VAN, $30 \mu \mathrm{g}$, Laboclin ${ }^{\circledR}$ ), ciprofloxacino (CIP, $5 \mu \mathrm{g}$, Laboclin ${ }^{\circledR}$ ), florfenicol (FLF, $30 \mu \mathrm{g}$, Sensifar ${ }^{\circledR}$ ), cefoxitina (CFO,30 $\mu \mathrm{g}$, Laboclin ${ }^{\circledR}$ ), gentamicina (GEN, $10 \mu \mathrm{g}$, Laboclin ${ }^{\circledR}$ ), neomicina (NEO, $30 \mu \mathrm{g}$, Laboclin $®$ ), tobramicina (TOB, $10 \mu \mathrm{g}$, Laboclin $®$ ), enrofloxacino (ENO, $5 \mu \mathrm{g}$, Sensifar ${ }^{\circledR}$ ), amicacina (AMI, $30 \mu \mathrm{g}$, Laboclin ${ }^{\circledR}$ ) e cefotaxima (CTX, $30 \mu \mathrm{g}$, Laboclin ${ }^{\circledR}$ ). Após a incubação, os halos de inibição foram medidos (em $\mathrm{mm}$ ) com o auxílio de um paquímetro digital. O controle foi feito da mesma forma descrita acima, utilizando o ágar Mueller Hinton sem adição do extrato e com adição do solvente DMSO.

\subsection{Análise Estatística}

As variáveis referentes às características mensuradas provenientes de seis diferentes extratos vegetais mais controle e oito diferentes cepas de micro-organismos, foram submetidas à análise de variância seguindo o delineamento inteiramente ao acaso, em três repetições (unidade experimental composta de 01 placa) em modelo estatístico baseado no arranjo fatorial:

$Y_{i j k}=\mu+E_{i}+M_{j}+E_{i} x M_{j}+\varepsilon_{i j k}$

Onde:

$\mu=$ constante geral;

$E_{i}=$ efeito do i-ésimo extrato e controle como sendo fixo $(i=1,2, \ldots, 8)$;

$\mathrm{M}_{\mathrm{j}}=$ efeito do j-ésimo microorganismo como sendo fixo $(\mathrm{j}=1,2, \ldots, 7)$;

$\mathrm{E}_{\mathrm{i}} \times \mathrm{M}_{\mathrm{j}}=$ efeito da interação extrato vs microorganismo;

$\varepsilon_{\mathrm{ijk}}=$ erro experimental, associado a cada observação, pressuposto NID $\left(0, \sigma^{2}\right)$.

Os graus de liberdade dos tratamentos assim como suas interações foram desdobrados via teste de médias Tukey a 5\% de probabilidade com uso do recurso computacional GENES (Cruz, 2013).

\section{RESULTADOS E DISCUSSÃO}

Houve significância para as fontes de variação micro-organismos, extratos e para a interação entre eles ao nível de $1 \%$ de probabilidade pelo teste $\mathrm{F}$ da análise de variância. $\mathrm{O}$ coeficiente de variação experimental foi da magnitude de $16,71 \%$, valor considerado baixo o que caracteriza um bom controle das condições experimentais.

Quando submetidos ao teste pelo método de difusão em ágar, os extratos, na concentração de $1 \mathrm{~g} / \mathrm{mL}$, inibiram o crescimento de todas as cepas testadas, apresentando halos de inibição variados (Tabela 1). De maneira geral, os extratos 1, 2, 5 e 6 apresentaram halos de inibição comparáveis aos halos formados pelo antibiótico de referência (gentamicina). Em relação à COL, cepa meticilina resistente, observou-se que os extratos 1,2 e 5 não diferiram entre si, apresentando ação antimicrobiana superior a gentamicina, que não formou nenhum halo na concentração testada e aos demais extratos, que não apresentaram halo de inibição.

Persp. online: biol. \& saúde, Campos dos Goytacazes, 20 (6), 1- 13, 2016

seer.perspectivasonline.com.br 
Tabela 1. Valores médios, em milímetros, dos diâmetros do halo de inibição provenientes dos tratamentos $(1=$ extrato em diclorometano de casca de $P$. granatum, $2=$ extrato metanólico de casca de $P$. granatum, $3=$ extrato em diclorometano de semente de $P$. granatum, $4=$ extrato metanólico de semente de $P$. granatum, $5=$ extrato metanólico de folhas de $P$. guajava, $6=$ extrato metanólico de folhas de $A$. occidentale e $\mathrm{G}=$ gentamicina).

\begin{tabular}{ccccccccc}
\hline \multirow{2}{*}{ Tratamento } & \multicolumn{7}{c}{ Micro-organismo } \\
\cline { 2 - 8 } & COL & $\begin{array}{c}\text { ATCC } \\
\mathbf{2 5 9 2 3}\end{array}$ & $\begin{array}{c}\text { LSA- } \\
\mathbf{8 8}\end{array}$ & RN6390B & $\begin{array}{c}\text { S. aureus } \\
\text { clínica }\end{array}$ & $\begin{array}{c}\text { S. } \\
\text { epidermidis }\end{array}$ & E. coli & $\begin{array}{c}\boldsymbol{P} \text {. } \\
\text { aeruginosa }\end{array}$ \\
\hline $\mathbf{1}$ & $16,00^{\mathrm{a}}$ & $25,00^{\mathrm{a}}$ & $11,66^{\mathrm{a}}$ & $10,33^{\mathrm{a}}$ & $28,00^{\mathrm{a}}$ & $30,00^{\mathrm{a}}$ & $24,66^{\mathrm{a}}$ & $10,66^{\mathrm{b}}$ \\
$\mathbf{2}$ & $15,00^{\mathrm{a}}$ & $27,00^{\mathrm{a}}$ & $8,00^{\mathrm{ab}}$ & $10,00^{\mathrm{a}}$ & $26,33^{\mathrm{a}}$ & $29,00^{\mathrm{a}}$ & $24,66^{\mathrm{a}}$ & $9,66^{\mathrm{bc}}$ \\
$\mathbf{3}$ & $0,00^{\mathrm{c}}$ & $13,66^{\mathrm{c}}$ & $3,66^{\mathrm{b}}$ & $0,00^{\mathrm{b}}$ & $8,33^{\mathrm{d}}$ & $5,66^{\mathrm{d}}$ & $0,00^{\mathrm{d}}$ & $0,00^{\mathrm{d}}$ \\
$\mathbf{4}$ & $0,00^{\mathrm{c}}$ & $21,66^{\mathrm{ab}}$ & $2,66^{\mathrm{b}}$ & $0,00^{\mathrm{b}}$ & $13,00^{\mathrm{cd}}$ & $13,66^{\mathrm{c}}$ & $9,33^{\mathrm{c}}$ & $2,66^{\mathrm{d}}$ \\
$\mathbf{5}$ & $14,33^{\mathrm{ab}}$ & $23,33^{\mathrm{ab}}$ & $8,00^{\mathrm{ab}}$ & $13,33^{\mathrm{a}}$ & $18,00^{\mathrm{bc}}$ & $21,33^{\mathrm{b}}$ & $15,33^{\mathrm{bc}}$ & $8,33^{\mathrm{bc}}$ \\
$\mathbf{6}$ & $7,33^{\mathrm{bc}}$ & $17,33^{\mathrm{bc}}$ & $12,00^{\mathrm{a}}$ & $15,33^{\mathrm{a}}$ & $18,00^{\mathrm{bc}}$ & $19,00^{\mathrm{bc}}$ & $13,33^{\mathrm{c}}$ & $6,66^{\mathrm{bcd}}$ \\
$\mathbf{G}$ & $0,00^{\mathrm{c}}$ & $27,00^{\mathrm{a}}$ & $13,00^{\mathrm{a}}$ & $12,66^{\mathrm{a}}$ & $23,33^{\mathrm{ab}}$ & $24,66^{\mathrm{ab}}$ & $22,66^{\mathrm{ab}}$ & $19,00^{\mathrm{a}}$ \\
\hline
\end{tabular}

Médias seguidas de pelo menos uma letra na coluna (micro-organismo) não diferem entre si pelo teste de Tukey, ao nível de 5\% de significância.

Cada extrato foi considerado ativo quando apresentou halo de inibição comparável ao promovido pelo antibiótico padrão (gentamicina $10 \mu \mathrm{g} / \mathrm{ml}$ ), que apresentou halos com medidas variando entre 0 e $27 \mathrm{~mm}$ de diâmetro. O DMSO que teve a finalidade de solubilizar os extratos, não apresentou nenhuma atividade frente às cepas testadas, (Figura 1), atendendo o requisito básico de um solvente utilizado para este fim.

\subsection{Avaliação da sensibilidade de diferentes micro-organismos aos extratos brutos}

\subsubsection{Efeito dos extratos isolados frente à cepa COL (meticilina resistente)}

Os extratos 1 (halo $16 \mathrm{~mm}$ ) e 2 (halo $15 \mathrm{~mm}$ ) nas concentrações de $1 \mathrm{~g} / \mathrm{mL}$.apresentaram atividade antimicrobiana significativamente superior $(\mathrm{p}<0,05)$ ao antibiótico de referência (gentamicina), que não apresentou nenhum halo de inibição na concentração de $10 \mathrm{mg} / \mathrm{mL}$, conforme ilustra a Figura 1 . Resultados similares foram encontrados por Carlos et al. (2010), quando avaliou a atividade antimicrobiana dos extratos metanólicos das cascas das raízes de Rauvolfia grandiflora e das folhas de Rauvolfia mattfeldiana (Carlos, 2007), ambos com concentração de $42 \mu \mathrm{g} / \mathrm{mL}$, no qual apresentaram diâmetros do halo de inibição igual a 13,9 e $12,2 \mathrm{~mm}$ respectivamente.

\subsection{2. $\quad$ Efeito dos extratos isolados frente à cepa ATCC 25923}

Os extratos 1 (halo $25 \mathrm{~mm}$ ) e 2 (halo $27 \mathrm{~mm}$ ) nas concentrações de $1 \mathrm{~g} / \mathrm{mL}$ apresentaram maior atividade antimicrobiana e não se diferiram $(\mathrm{p}<0,05)$ da gentamicina (halo $27 \mathrm{~mm})$, na concentração de $10 \mathrm{mg} / \mathrm{mL}$, conforme demonstrado na Tabela 1 . Os extratos $4(21,66 \mathrm{~mm})$ e $5(23,33 \mathrm{~mm})$, embora tenham apresentado menores diâmetros, também não se diferiram significativamente do antibiótico de referência.

\subsubsection{Efeito dos extratos isolados frente à cepa LSA-88 enterotoxigênica}

Os extratos 1 (halo 11,66 mm) e 6 (halo $12 \mathrm{~mm}$ ) apresentaram maior atividade antimicrobiana e não se diferiram significativamente da gentamicina $(13 \mathrm{~mm})$ que apresentou maior diâmetro do halo de inibição. Os demais extratos apresentaram halos de inibição menores e não se diferiram entre si.

Persp. online: biol. \& saúde, Campos dos Goytacazes, 20 (6), 1- 13, 2016

seer.perspectivasonline.com.br 


\subsubsection{Efeito dos extratos isolados frente à cepa RN6390B}

Os extratos $1(10,33 \mathrm{~mm}), 2(10 \mathrm{~mm}), 5(13,33 \mathrm{~mm})$ e $6(15,33 \mathrm{~mm})$ apresentaram maior atividade antimicrobiana e não se diferiram significativamente da gentamicina, que apresentou halo de inibição igual a $12,66 \mathrm{~mm}$. Os demais extratos não apresentaram halo de inibição.

\subsubsection{Efeito dos extratos isolados frente à cepa $S$. aureus cepa clínica}

Os extratos 1 e 2 apresentaram maior atividade antimicrobiana ( 28 e $26,33 \mathrm{~mm}$, respectivamente), sendo superior a atividade do antibiótico de referência (na concentração de $10 \mathrm{mg} / \mathrm{mL}$ ) que apresentou halo de inibição igual a $23,33 \mathrm{~mm}$. Os demais extratos apresentaram menores halos de inibição e não diferiram significativamente entre si.

\subsubsection{Efeito dos extratos isolados frente à cepa $S$. epidermidis}

Os extratos 1 e 2 apresentaram efeito inibitório sobre essa cepa, com halos de inibição de 28 e 26,33 $\mathrm{mm}$, respectivamente, sendo superior a gentamicina (halo $23,33 \mathrm{~mm}$ ), como ilustra a Figura 1 . Os extratos 5 e 6 não diferiram entre si. Os extratos 3 e 4 apresentaram menor atividade antimicrobiana.

\subsubsection{Efeito dos extratos isolados frente à cepa Escherichia coli}

Os extratos 1 e 2 (halos 24,66 mm) apresentaram maior halo de inibição entre os extratos e não diferiram significativamente da gentamicina que apresentou halo igual a 22,66 mm. Os extratos 4, 5 e 6 não se diferiram entre si. O extrato 3 não apresentou atividade frente a $E$. coli, nas condições avaliadas.

\subsubsection{Efeito dos extratos isolados frente à Pseudomonas aeruginosa}

Os halos de inibição apresentados pelos extratos $1(10,66 \mathrm{~mm}), 2(9,66 \mathrm{~mm}), 5(8,33 \mathrm{~mm})$ e $6(6,66$ $\mathrm{mm})$ não diferiram entre si e foram menores que o halo apresentado pelo antibiótico de referência (19 $\mathrm{mm})$, conforme pode-se observar na Figura 1. Os demais extratos não apresentaram efeito sobre a sensibilidade desta cepa.

Tabela 2. Valores médios, em milímetros, do diâmetro do halo de inibição provenientes dos tratamentos $(1=$ extrato em diclorometano de casca de $P$. granatum, $2=$ extrato metanólico de casca de $P$. granatum, 3= extrato em diclorometano de semente de $P$. granatum, $4=$ extrato metanólico de semente de $P$. granatum, $5=$ extrato metanólico de folhas de $P$. guajava, $6=$ extrato metanólico de folhas de $A$. occidentale e $\mathrm{G}=$ gentamicina).

\begin{tabular}{lccccccc}
\hline \multirow{2}{*}{ Micro-organismo } & $\mathbf{1}$ & $\mathbf{2}$ & $\mathbf{3}$ & $\mathbf{4}$ & $\mathbf{5}$ & $\mathbf{6}$ & G \\
\hline COL & $16,00^{\mathrm{b}}$ & $15,00^{\mathrm{b}}$ & $0,00^{\mathrm{c}}$ & $0,00^{\mathrm{d}}$ & $14,33^{\mathrm{bcd}}$ & $7,33^{\mathrm{b}}$ & $0,00^{\mathrm{d}}$ \\
ATCC 25923 & $25,00^{\mathrm{a}}$ & $27,00^{\mathrm{a}}$ & $13,22^{\mathrm{a}}$ & $21,66^{\mathrm{a}}$ & $23.33^{\mathrm{a}}$ & $17,33^{\mathrm{a}}$ & $27,00^{\mathrm{a}}$ \\
LSA-88 & $11,66^{\mathrm{b}}$ & $8,00^{\mathrm{b}}$ & $3,66^{\mathrm{bc}}$ & $2,66^{\mathrm{cd}}$ & $8,00^{\mathrm{d}}$ & $12,00^{\mathrm{ab}}$ & $13,00^{\mathrm{c}}$ \\
RN6390B & $10,33^{\mathrm{b}}$ & $10,00^{\mathrm{b}}$ & $0,00^{\mathrm{c}}$ & $0,00^{\mathrm{d}}$ & $13,33^{\mathrm{cd}}$ & $15,33^{\mathrm{a}}$ & $12,66^{\mathrm{c}}$ \\
S. aureus clínica & $28,00^{\mathrm{a}}$ & $26,33^{\mathrm{a}}$ & $8,33^{\mathrm{ab}}$ & $13,00^{\mathrm{b}}$ & $18,33^{\mathrm{abc}}$ & $18,00^{\mathrm{a}}$ & $23,33^{\mathrm{ab}}$ \\
S. epidermidis & $30,00^{\mathrm{a}}$ & $29,00^{\mathrm{a}}$ & $5,66^{\mathrm{bc}}$ & $13,66^{\mathrm{b}}$ & $21,33^{\mathrm{ab}}$ & $19,00^{\mathrm{a}}$ & $24,66^{\mathrm{ab}}$ \\
E. coli & $24,66^{\mathrm{a}}$ & $24,66^{\mathrm{a}}$ & $0,00^{\mathrm{c}}$ & $9,33^{\mathrm{bc}}$ & $15,33^{\mathrm{bcd}}$ & $13,33^{\mathrm{ab}}$ & $22,66^{\mathrm{ab}}$ \\
P. aeruginosa & $10,66^{\mathrm{b}}$ & $9,66^{\mathrm{b}}$ & $0,00^{\mathrm{c}}$ & $2,66^{\mathrm{cd}}$ & $8,33^{\mathrm{d}}$ & $6,66^{\mathrm{b}}$ & $19,00^{\mathrm{bc}}$ \\
\hline
\end{tabular}

Médias seguidas de pelo menos uma letra na coluna (tratamento) não diferem pelo teste de Tukey, ao nível de 5\% de significância. 


\subsection{Avaliação do efeito de cada extrato sobre diferentes micro-organismos}

Os extratos 1 e 2 apresentaram maior inibição para as cepas ATCC 25923, S.aureus clínica, $S$. epidermidis e E.coli. As cepas de COL, LSA-88, RN6390B e P. aeruginosa não se diferiram quanto a medida do halo de inibição.

O extrato 3 apresentou maior atividade inibitória para a cepa ATCC 25923. As cepas LSA-88, S.aureus clínica e S. epidermidis não se diferiram. As cepas COL, RN6390B, Escherichia coli e Pseudomonas aeruginosa não apresentaram sensibilidade frente a este extrato. Mayachiew e Devahastin (2008) constataram que extratos etanólicos de Phyllanthus emblica Linn. e Alpinia galang apresentaram atividade inibitória significativa do crescimento Staphylococcus aureus ATCC 25923, de pelo método da difusão em disco.

O extrato 4 apresentou maior efeito inibitório para a cepa ATCC 25923. As cepas S.aureus clínica, $S$. epidermidis e Escherichia coli não diferiram significativamente entre si. Não foi observado nenhum efeito deste extrato sobre as cepas COL, LSA-88, RN6390B e Pseudomonas aeruginosa. Catão et al. (2006) avaliaram a atividade antimicrobiana de diferentes concentrações do extrato etanólico de P.granatum frente a 17 amostras de $S$. aureus, onde observaram que todas as cepas apresentaram sensibilidade ao extrato, na concentração de $10 \%$.

O extrato 5 apresentou maior inibição para as cepas ATCC 25923, S.aureus clínica e S. epidermidis. Para as demais cepas não houve diferença significativa. Iha et al. (2008) confirmaram a presença de taninos, possíveis responsáveis pela atividade antimicrobiana, do extrato etanólico dos frutos de $P$. guajava, além de terem verificado que a concentração de $50 \mu \mathrm{g} / \mathrm{mL}$ de tal extrato foi suficiente para inibir o crescimento de $S$. epidermidis e a concentração de $75 \mu \mathrm{g} / \mathrm{mL}$ foi suficiente para inibir o crescimento de $S$. aureus, porém extrato etanólico não inibiu o crescimento de E. coli. Por outro lado, Carvalho et al. (2002) concluíram que os extratos hidroalcoólicos da folha de $P$. granatum numa concentração de $2,4 \mathrm{mg} / \mathrm{mL}$ foi suficiente para inibir o crescimento de E. coli e Salmonella spp e a concentração de $1,8 \mathrm{mg} / \mathrm{mL}$ foi suficiente para inibir o crescimento de Pseudomonas aeruginosa, Shigella spp e Proteus spp.

O extrato 6 apresentou maior diâmetro do halo de inibição para as cepas ATCC 25923, RN6390B, S.aureus clínica e S. epidermidis. Para as demais cepas foi observado a formação de halos com diâmetros inferiores aos citados anteriormente e que não houve diferença significativa entre elas. A atividade antimicrobiana do extrato hidroalcóolico de A. occidentale, numa concentração de $6,25 \mathrm{mg} / \mathrm{mL}$, sobre as linhagens de Staphylococcus aureus de origem humana hospitalar multiresistentes (MRSA) e a uma concentração de $3,1 \mathrm{mg} / \mathrm{mL}$ do extrato sobre $S$. aureus sensíveis a meticilina (MSSA) foi demonstrada por SILVA, et al. (2007). Por outro lado, Ramalhete et al. (2011) avaliaram a capacidade de extratos de Momordica balsamina L., frente a diversas cepas de Staphylococcus aureus, incluindo a MRSA (resistente à meticilina), e não observaram inibição significativa.

Persp. online: biol. \& saúde, Campos dos Goytacazes, 20 (6), 1- 13, 2016

seer.perspectivasonline.com.br 

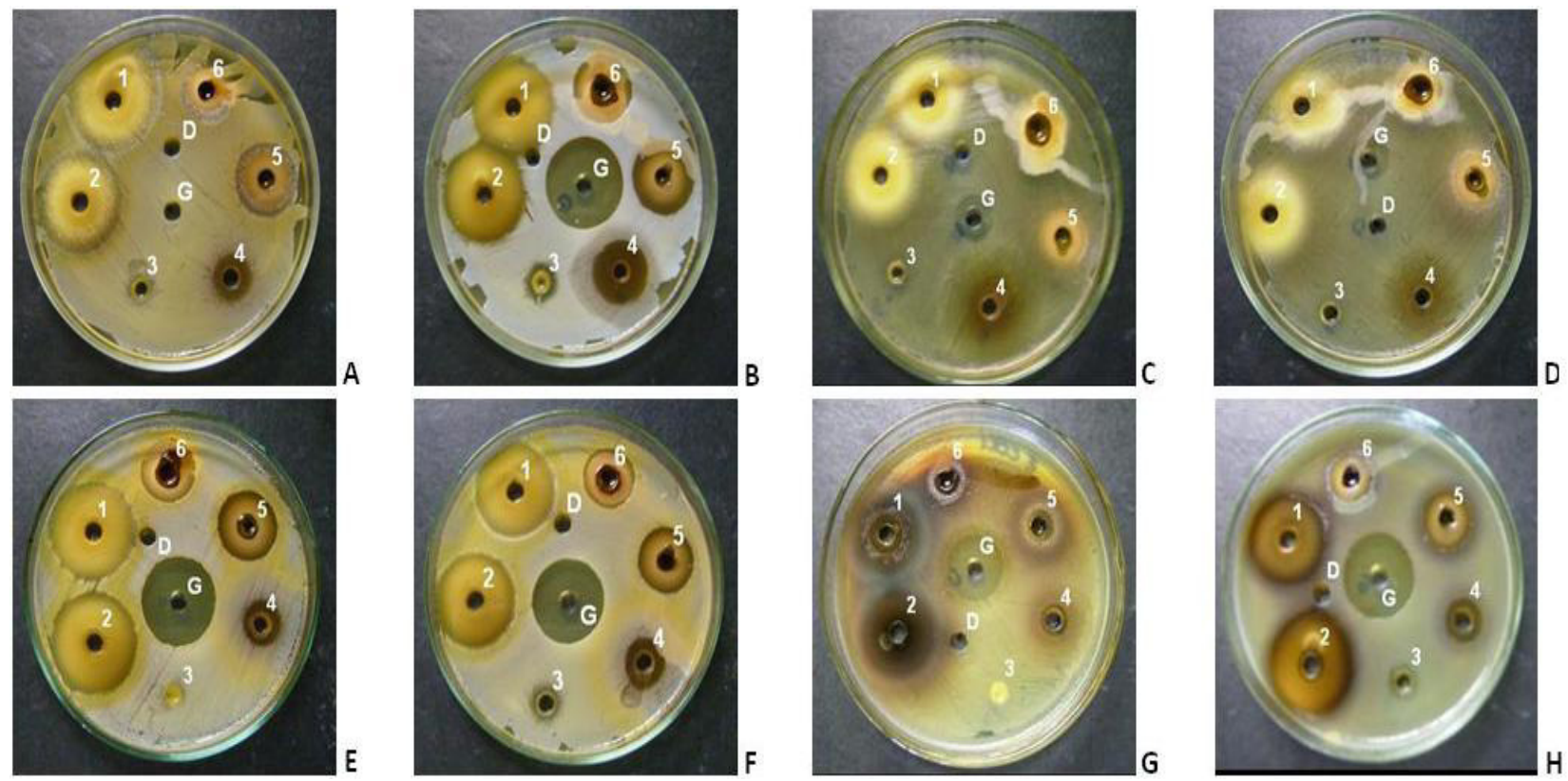

Figura 1. Avaliação da atividade antimicrobiana dos extratos $(1=$ extrato em diclorometano de casca de $P$. granatum, $2=$ extrato metanólico de casca de $P$. granatum, $3=$ extrato em diclorometano de semente de $P$. granatum, $4=$ extrato metanólico de semente de $P$. granatum, 5= extrato metanólico de folhas de $P$. guajava, $6=$ extrato metanólico de folhas de $A$. occidentale, $\mathrm{G}=$ gentamicina e $\mathrm{D}=\mathrm{DMSO})$ frente a micro-organismos $(\mathrm{A}=\mathrm{COL}, \mathrm{B}=\mathrm{ATCC} 25923, \mathrm{C}=$ $\mathrm{LSA}-88, \mathrm{D}=\mathrm{RN}, \mathrm{E}=S$. aureus clínica, $\mathrm{F}=S$. epidermidis, $\mathrm{G}=$ E. coli $\mathrm{e} \mathrm{H}=P$. aeruginosa $)$.

\subsection{Avaliação do efeito sinérgico entre extrato vegetal e antibióticos padrão}

\subsubsection{Efeito sinérgico das associações frente a bactérias Gram-positivas}

Quando as bactérias Gram-positivas (cepas de S. aureus e S. epidermidis) foram cultivadas na presença dos extratos associados aos antibióticos padronizados, foi observado um aumento na zona de inibição em torno dos discos para a maioria das drogas testadas quando comparadas ao controle (MH), conforme apresentado na Tabela 3. Em relação à cepa ATCC 25923, houve sinergismo do extrato com os antibióticos AMC, PEN e VAN. As demais associações não apresentaram halo de inibição, sendo comparáveis ao controle (MH). Para a cepa COL, somente as associações do extrato 6 com os antibióticos AMC, PEN e VAN apresentaram efeito sinérgico.

Para a cepa LSA-88, o extrato 2 testado individualmente, na concentração de $1 \mathrm{~g} / \mathrm{ml}$, apresentou o diâmetro do halo de inibição de $8 \mathrm{~mm}$, porém, quando associado com antibióticos padrões apresentou diâmetros de halos de inibição de 19,3 a $31,7 \mathrm{~mm}$, apontando para uma potencialização dos referidos antibióticos. As associações dos extratos 5 e 6 com o antibiótico SUT e 6 com CLI não apresentaram efeito sobre a sensibilidade desta cepa, conforme pode ser observado na Tabela 3. Para as demais associações, houve efeito sinérgico (Tabela 3).

Em relação à cepa RN6390B, todas as associações apresentaram efeito sinérgico, exceto as associações dos extratos com o antibiótico TET (Tabela 3), que não apresentaram nenhum halo de inibição, sendo, portanto, semelhantes ao controle. 
Tabela 3. Atividade de sinergismo dos extratos $(2=$ extrato metanólico de casca de $P$. granatum, $5=$ extrato metanólico de folhas de $P$. guajava e $6=$ extrato metanólico de folhas de $A$. occidentale) associados a antibióticos padronizados frente a bactérias Gram-positivas (cepas de $S$. aureus e $S$. epidermidis) medido pela formação de zona de inibição ao redor das colônias. Antibióticos: tetraciclina (TET, $30 \mu \mathrm{g}$, Laboclin®), cotrimoxazol (SUT, $25 \mu \mathrm{g}$, Laboclin ${ }^{\circledR}$ ), clindamicina (CLI, $2 \mu \mathrm{g}$, Laboclin ${ }^{\circledR}$ ), amoxicilina + ácido clavulânico (AMC, 20/10 $\mu \mathrm{g}$, Sensifar®), penicilina (PEN, 10 UI, Sensifar®), eritromicina (ERI, $15 \mu \mathrm{g}$, Laboclin ${ }^{\circledR}$ ) e vancomicina (VAN, $30 \mu \mathrm{g}$, Laboclin®).

\begin{tabular}{|c|c|c|c|c|c|c|c|c|}
\hline \multirow{2}{*}{$\begin{array}{c}\text { Micro- } \\
\text { organismo }\end{array}$} & \multirow{2}{*}{ Tratamento } & \multicolumn{7}{|c|}{$\begin{array}{c}\text { Antibiótico } \\
\text { Zonas de inibição (mm) } \\
\end{array}$} \\
\hline & & TET & SUT & CLI & AMC & PEN & ERI & VAN \\
\hline \multirow{4}{*}{ ATCC 25923} & MH & 0,0 & 0,0 & 0,0 & 24,3 & 8,3 & 0,0 & 15,7 \\
\hline & Extrato 2 & 0,0 & 0,0 & 0,0 & 33,7 & 12,7 & 0,0 & 20,7 \\
\hline & Extrato 5 & 0,0 & 0,0 & 0,0 & 28,0 & 10,3 & 0,0 & 19,0 \\
\hline & Extrato 6 & 0,0 & 0,0 & 0,0 & 31,7 & 12,3 & 0,0 & 22,7 \\
\hline \multirow{4}{*}{ COL } & MH & 0,0 & 0,0 & 0,0 & 19,7 & 8,3 & 0,0 & 20,0 \\
\hline & Extrato 2 & 0,0 & 0,0 & 0,0 & 18,7 & 8,3 & 0,0 & 20,0 \\
\hline & Extrato 5 & 0,0 & 0,0 & 0,0 & 19,0 & 8,5 & 0,0 & 19,7 \\
\hline & Extrato 6 & 0,0 & 0,0 & 0,0 & 20,7 & 9,3 & 0,0 & 21,3 \\
\hline \multirow{4}{*}{ LSA-88 } & MH & 0,0 & 14,0 & 21,7 & 26,7 & 16,0 & 20,3 & 19,3 \\
\hline & Extrato & 0,0 & 19,3 & 23,0 & 31,7 & 20,3 & 24,0 & 21,7 \\
\hline & Extrat & 0,0 & 0,0 & 10,3 & 30,3 & 18,3 & 23,3 & 22,3 \\
\hline & Extrato & 0,0 & 0,0 & 0,0 & 31,0 & 17,7 & 15,0 & 20,3 \\
\hline \multirow{4}{*}{ RN6390B } & MH & 0,0 & 14,0 & 19,3 & 23,7 & 14,3 & 18,0 & 18,0 \\
\hline & Extrato 2 & 0,0 & 21,7 & 23,0 & 33,0 & 23,7 & 22,7 & 20,3 \\
\hline & Extrato 5 & 0,0 & 17,7 & 23,7 & 29,7 & 17,7 & 22,3 & 20,7 \\
\hline & Extrato 6 & 0,0 & 26,3 & 22,3 & 28,7 & 17,3 & 22,3 & 20,3 \\
\hline \multirow{4}{*}{$\begin{array}{l}\text { S. aureus } \\
\text { clínica }\end{array}$} & MH & 25,7 & 23,3 & 0,0 & 23,0 & 15,3 & 0,0 & 16,0 \\
\hline & Extrato & 27,0 & 23,7 & 0,0 & 25,7 & 15,7 & 0,0 & 18,3 \\
\hline & Extrato 5 & 25,7 & 23,7 & 0,0 & 23,3 & 14,0 & 0,0 & 16,7 \\
\hline & Extrato 6 & 28,0 & 32,0 & 0,0 & 31,0 & 19,7 & 0,0 & 20,3 \\
\hline \multirow{4}{*}{ S. epidermidis } & & 22,3 & 23,3 & 20,7 & 29,0 & 14,7 & 18,3 & 14,0 \\
\hline & Extrato 2 & 26,3 & 24,0 & 25,0 & 31,7 & 19,7 & 21,7 & 18,0 \\
\hline & Extrato 5 & 24,3 & 22,7 & 23,0 & 28,3 & 17,3 & 20,7 & 17,0 \\
\hline & Extrato 6 & 25,0 & 31,7 & 26,0 & 35,7 & 19,7 & 24,3 & 19,7 \\
\hline
\end{tabular}

Para a cepa $S$. aureus clínica, as associações apresentaram efeito sinérgico, todavia, quando os extratos foram associados aos antibióticos CLI e ERI não houve atividade antimicrobiana, como foi apresentado pelo controle. Para a cepa S. epidermidis, em geral houve sinergismo para todas as associações em relação ao controle.

De maneira geral, o efeito sinérgico foi satisfatório dos extratos utilizados, visto que, houve uma potencialização do efeito antimicrobiano após sua associação com os antibióticos.

\subsection{Efeito sinérgico das associações frente a bactérias Gram-negativas}

Em relação às bactérias Gram-negativas ( $P$. aeruginosa e $E$. coli), quando cultivadas na presença dos extratos associados aos antibióticos padronizados, observou-se que não houve sinergismo em nenhuma das associações realizadas, como está indicado na Tabela 4.

Persp. online: biol. \& saúde, Campos dos Goytacazes, 20 (6), 1- 13, 2016

seer.perspectivasonline.com.br 
Tabela 4. Atividade de sinergismo dos extratos $(2=$ extrato metanólico de casca de $P$. granatum, $5=$ extrato metanólico de folhas de $P$. guajava e $6=$ extrato metanólico de folhas de $A$. occidentale) associados a antibióticos padrão frente a bactérias gram-negativas ( $P$. aeruginosa e $E$. coli) medido pela formação de zona de inibição ao redor das colônias.

\begin{tabular}{cccccccccccccc}
\hline \multirow{2}{*}{$\begin{array}{c}\text { Micro- } \\
\text { organismo }\end{array}$} & Tratamento & \multicolumn{10}{c}{$\begin{array}{c}\text { Antibiótico } \\
\text { Zonas de inibição (mm) }\end{array}$} \\
\cline { 3 - 12 } & & MH & - & - & 40,3 & - & - & 23,0 & 21,0 & 26,7 & 26,0 & 25,3 & 21,7 \\
\multirow{3}{*}{$\begin{array}{c}\text { P. aeruginosa } \\
\end{array}$} & Extrato 2 & - & - & 32,7 & - & - & 16,7 & 15,3 & 20,3 & 21,3 & 17,7 & 22,0 \\
& Extrato 5 & - & - & 31,3 & - & - & 19,3 & 18,7 & 23,3 & 21,0 & 23,0 & 21,0 \\
& Extrato 6 & - & - & 40,0 & - & - & 20,3 & 17,3 & 24,3 & 26,7 & 23,3 & 24,0 \\
\hline \multirow{3}{*}{ E. coli } & MH & 28,0 & 36,3 & 40,7 & 29,3 & 30,0 & 25,0 & - & - & - & - & - \\
& Extrato 2 & 24,0 & 21,7 & 34,0 & 31,3 & 27,0 & 14,3 & - & - & - & - & - \\
& Extrato 5 & 23,3 & 24,7 & 32,0 & 27,3 & 27,0 & 21,0 & - & - & - & - & - \\
& Extrato 6 & 23,7 & 31,7 & 37,7 & 28,3 & 30,7 & 21,7 & - & - & - & - & - \\
\hline
\end{tabular}

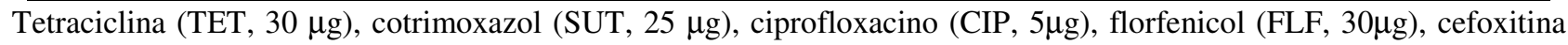
$(\mathrm{CFO}, 30 \mu \mathrm{g}$ ), gentamicina (GEN, $10 \mu \mathrm{g}$ ), neomicina (NEO, 30 $\mu \mathrm{g}$ ), tobramicina (TOB, $10 \mu \mathrm{g}$ ), enrofloxacino (ENO, 5

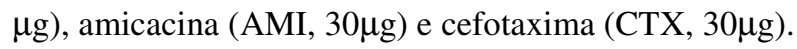

\section{CONCLUSÕES}

Os extratos diclorometânico e metanólico das cascas dos frutos de Punica granatum e metanólicos das folhas de Anacardium occidentale e Psidium guajava, na concentração de $1 \mathrm{~g} / \mathrm{mL}$, apresentaram atividade antimicrobiana frente a $S$. epidermidis, E.coli e as cinco cepas de S. aureus: COL (meticilina resistente), ATCC 25923, LSA-88 (enterotoxigênica), RN6390B (arg positiva) e S. aureus cepa clínica (isolada de úlcera humana). Os extratos diclorometânico e metanólico da semente de Punica granatum não apresentaram atividade antimicrobiana satisfatória frente às cepas testadas na concentração de $1 \mathrm{~g} / \mathrm{mL}$.

As associações dos extratos metanólicos de $P$. granatum, $P$. guajava e A. occidentale com antibióticos padronizados apresentaram uma potencialização do efeito antimicrobiano frente a bactérias Gram-positivas, sugerindo efeito de sinergismo entre os mesmos, mas necessitando de confirmação em estudos complementares. Quando essas associações foram testadas nas bactérias Gram-negativas, observou-se que não houve efeito sinérgico.

A complementação desse estudo, envolvendo a purificação e identificação dos componentes bioativos nos extratos testados nas concentrações de $1 \mathrm{~g} / \mathrm{mL}$ podem levar ao isolamento de princípios ativos contribuindo para o desenvolvimento de drogas com atividade potencial ao combate de infecções causadas pelos micro-organismos testados.

\section{REFERÊNCIAS}

AZEVEDO, S.K.S. \& SILVA, I.M. Plantas medicinais e de uso religioso comercializadas em mercados e feiras livres no Rio de Janeiro, RJ, Brasil. Acta Botânica Brasílica, v.20, n.1, p. 185-194, 2006.

BARBOSA, R. C. S. B; GIESBRECHT, A. M.; BARBOSA FILHO, J. M.; GOTTLIEB, O. R. Avaliação da atividade antibiótica de extrato de Lauraceae. Acta amazônica, v. 18, p. 91-94, 1988.

BHOWMIK, D.; GOPINATH1, H.; KUMAR, B.P.; DURAIVEL, S.; ARAVIND. G., KUMAR, K.P.S. Medicinal Uses of Punica granatum and its health benefits. Journal of Pharmacognosy and Phytochemistry, v.1, n. 5, p. 28-33, 2013.

Persp. online: biol. \& saúde, Campos dos Goytacazes, 20 (6), 1- 13, 2016

seer.perspectivasonline.com.br 
CARLOS, L. A. Alcalóides de Rauvolfia grandiflora e de Rauvolfia mattfeldiana (Apocynaceae). Campos dos Goytacazes: Universidade Estadual do Norte Fluminense Darcy Ribeiro (UENF), 2007. 196 f. Tese (Doutorado em Produção Vegetal) - Programa de Pós-Graduação em Produção Vegetal, UENF, Campos dos Goytacazes, 2007.

CARLOS, L. A. ; AMARAL, K. A. S. ; VIEIRA, I. J. C. ; MATHIAS,L. ; BRAZ-FILHO; SAMARÃO, S. S. ; MOTTA , O.V. . Rauvolfia grandiflora (Apocynaceae) extract interferes with staphylococcal density, enterotoxin production and antimicrobial activity. Brazilian Journal of Microbiology, v. 41, p. 612-620, 2010.

CARVAlHO, A. A. T.; SAMPAIO, M. C.C.; SAMPAIO, F. C.; MElO, A.F. M.; SENA, K.X. F. R.; CHIAPPETA, A. A.; HIGINO, J. S. Atividade Antimicrobiana in vitro de extratos hidroalcoólicos de Psidium guajava L. sobre bactérias gram-negativas. Acta Farmacêutica Bonaerense, v. 21, n. 4, p. 255-258, 2002.

CATÃO, R. M. R; ANTUNES, R. M. P; ARRUdA, T. A; PEREIRA, M. S. V; HIGINO, J. S; ALVES, J. A; PASSOS, M. G. V. M; SANTOS, V. L. Atividade antimicrobiana "in vitro" do extrato etanólico de Punica granatum linn (romã) sobre isolados ambulatoriais de Staphylococcus aureus. Revista Brasileira de Análises Clínicas, v.38, n.2, p.111-114, 2006.

CRUZ, C.D GENES - a software package for analysis in experimental statistics and quantitative genetics. Acta Scientiarum Agronomy, v.35, n.3, p.271-276, 2013.

IHA, S. M MigliatO, K. F.; VELlOSA J. C. R.; SACRAMENTO, L. V. S; PIETRO, R. C. L. R.; ISAAC, V. L. B.; BRUNETTI, I. L.; CORRÊA, M. A.; SALGADO, H. R. N. Estudo fitoquímico de goiaba (Psidium guajava L.) com potencial antioxidante para o desenvolvimento de formulação fitocosmética. Revista Brasileira de Farmacognosia, v.18, n.3, p. 387-393, 2008.

MACHADO, T. B.; LEAL, I. C. R.; AMARAL, A. C. F.; SANTOS, K. R. N.; SILVA, M. G.; KUSTER, R. M. Antimicrobial ellagitannin of Punica granatum fruits. Journal of the Brazilian Chemical Society, v.13, n.5, p.606-610, 2002.

MAYACHIEW, P.; DEVAHASTIN, S. Antimicrobial and antioxidant activities of Indian gooseberry and galangal extracts. LWT- Food Science and Technology, v. 41, p.1153-1159, 2008.

MIGUEL, M.G.; NEVES, M. A.; ANTUNES, M. D. Pomegranate (Punica granatum L.): A medicinal plant with myriad biological properties - A short review, Journal of Medicinal Plants Research, v.4, n. 25, p. 2836$2847,2010$.

RAMAlHete, C., SPENGLER, G., MARTINS, A., MARTINS, M., VIVEIROS, M., MUlHOVO, S., FERREIRA, M.J.U., AMARAL, L. Inhibition of efflux pumps in meticillin-resistant Staphylococcus aureus and Enterococcus faecalis resistant strains by triterpenoids from Momordica balsamina. International Journal of Antimicrobial Agents. n. 37, p.70-74, 2011.

ROJAS, R.; BUSTAMATE, B.; VENTOSILLA, P.; FERNÁNDEZ, I.; CAVIEDES, L.; GILMAN, R.H.; LOCK, O.; HAMMOND, G.B. Larvicidal, antimicobacterical and antifungal coumponds from bark of the Peruvian Plant Swartzia polyphylla DC. Chemical \& Pharmaceutical Bulletin, v. 54, p. 278-279, 2006.

ROSSI, F. \& ANDREAZZI, D.B. Resistência bacteriana: interpretando o antibiograma. São Paulo: Atheneu; 2005.

Persp. online: biol. \& saúde, Campos dos Goytacazes, 20 (6), 1- 13, 2016

seer.perspectivasonline.com.br 
SILVA, J. G. ; SOUZA, I. A.; HIGINO, J.S.; SIQUEIRA-JUNIOR, J. P.; PEREIRA, J.V.; PEREIRA, M.S.V. Atividade antimicrobiana do extrato de Anacardium occidentale Linn. em amostras multiresistentes de Staphylococcus aureus. Revista Brasileira de Farmacognosia, v.17, n.4, p.572-577, 2007.

VARGAS, A. C.; LOGUERCIO, A. P.; WITT, N. M.; COSTA, M. M.; SILVA, M.S.; VIANA, L. R. Atividade antimicrobiana "in vitro" de extrato alcoólico de própolis. Ciência Rural, v.34, n. 1, p. 159-163, 2004.

WERKMAN, C.; GRANATO, D.C.; KERBAUY, W.D.; SAMPAIO, F.C.; BRANDÃO, A.A.H.; RODE, S.M. Aplicações terapêuticas da Punica granatum L. (romã). Revista Brasileira de Plantas Medicinais, v.10, n.3, p.104-111, 2008.

YUNES, R.A.; CALIXTO, J.B. Plantas medicinais sob a ótica da química medicinal moderna, Chapecó: Argos Editora Universitária, 2001. 